\title{
Feiring's concept of forward-looking responsibility: a dead end for responsibility in healthcare.
}

\author{
Andreas Albertsen \\ Department of Political Science, Aarhus University \\ aba@ps.au.dk
}

This is a post print version. Published version located here

Albertsen, A. (2015). Feiring's concept of forward-looking responsibility: a dead end for responsibility in healthcare. Journal of Medical Ethics, 41(2), 161-164.

http://doi.org/10.1136/medethics-2013-101563

Feiring's concept of forward-looking responsibility: a dead end for responsibility in healthcare

\section{ABSTRACT}

Eli Feiring has developed a concept of forward-looking responsibility in healthcare. On this account, what matters morally in the allocation of scarce healthcare resources is not people's past behaviours but rather their commitment to take on lifestyles that will increase the benefit acquired from received treatment. According to Feiring, this is to be preferred over the backward-looking concept of responsibility often associated with luck egalitarianism. The article critically scrutinizes Feiring's position. It begins by spelling out the wider implications of Feiring's view. Against this background, it shows that (i) Feiring's distinction between backward and forward-looking responsibility is incompatible with the Scanlonian notion of responsibility she apparently endorses; (ii) her favoured forward looking notion of responsibility is subject to the objections leveled against other luck egalitarian views (whatever the strength of such objections). 


\section{INTRODUCTION}

In a time of increasing healthcare costs, strained public budgets and changing patterns of disease, the discussions over how society should allocate scarce healthcare resources is often influenced by an idea of personal responsibility. The burden from non-communicable chronic diseases is pivotal to this discussion, and much attention has been given to lifestyle related chronic diseases. Some suggest that when people's choices result in a greater need for healthcare, we should give them lower priority, than those who are suffering from diseases unrelated to their own choices. In many ways, this corresponds to a central intuition of luck egalitarianism; an influential theory of distributive justice. Luck egalitarians assert that distributions are just, if and only if, people's relative positions reflect their exercises of responsibility.[1] The luck egalitarian approach is concerned with people's past choices, how they have hitherto exercised their responsibility, and, in that sense, it is backward-looking. Such notions of responsibility have gained much attention in the normative debate on allocation of healthcare.[2-11] In an interesting contribution to this discussion, Eli Feiring has proposed that when allocating scarce healthcare resources, we should abandon the backward-looking concept of responsibility.[12] Instead, we should be concerned with what she calls a forward-looking concept of responsibility. In short, it considers people's post-treatment lifestyle to be the right focus for a responsibility-catering approach to healthcare. Although it is developed in the context of obesity, Feiring clearly believes it is relevant for other diseases since she also mentions alcohol consumption and smoking in her discussion.[12]

To understand Feiring's notion of forward-looking responsibility, it is instructive to consider the two main reasons she offers for rejecting a backward-looking concept of responsibility. First, she submits that it is often both philosophically and practically difficult to assess whether something has happened as a consequence of choice or is more reasonably attributed to a person's circumstances. Second, she argues that the process of establishing whether some health disadvantage can be attributed to choice or circumstance may be intrusive, demeaning and shameful for the person under assessment.[12] Consequently, Feiring finds it necessary to abandon the idea of backward-looking responsibility in healthcare. This conclusion, however, does not imply that there is no room for responsibility in the allocation of scarce healthcare resources. Focus should rather be on 
the forward-looking responsibility. The content of this concept is explored in the next section.

\section{FORWARD-LOOKING RESPONSIBILITY}

Instead of a backward-looking concept of responsibility, Feiring proposes one that looks to the future. This section examines her reasoning when developing the concept and her reasons for preferring it. She maintains that, on a fundamental level, we should be concerned with how sick people are and with the expected positive effect of treatment. Furthermore, she maintains that "severely ill patients who are likely to respond well to treatment...should, under the specified understanding of medical need, be given priority over patients less likely to benefit."[12] It is in the pursuit of such considerations that the concept of forward-looking responsibility emerges. In accordance with Feiring's argument, consider the disease $x$, which people acquire both for reasons related to lifestyle $(r 1)$ and for reasons unrelated to lifestyle ( $\mathrm{r} 2$ ). Feiring's critique of backward-looking responsibility concludes that it would be wrong to give priority to the people whose disease is unrelated to lifestyle at the expense of those whose disease is in fact related to lifestyle. According to Feiring, this does not exhaust the role for personal responsibility in the way the healthcare system deals with $\mathrm{x}$ through the employment of medical intervention (i2). The concern for the expected benefit from treatment brings the idea of forward-looking responsibility into the discussion. As Fering reasonably stipulates, "several factors may reduce the expected benefit of treatment."[12] Some of the factors are circumstances beyond our control, while we may be in a position to improve upon other factors. Feiring counts our post-treatment lifestyle to be among the latter factors.[12] The lifestyle people pursue can adversely affect the outcome of the prescribed treatment in a wide range of cases. This includes people who consume alcohol after receiving a liver transplant, and people who eat to excess after receiving a bypass surgery. Feiring argues that we should give priority to people who are willing to commit to a change of lifestyle: "If the patient refuses, then she cannot reasonably complain to be given lower priority on the waiting list."[12]. Her suggestions for implementation is as follows: Two persons turns to the healthcare system with the disease $x$. Person A has a lifestyle which we know can lead to disease $x$, while person B does not. Whether person $A$ will receive treatment on equal terms with person $B$ depends on his willingness to sign a contract declaring a commitment to undertake medical follow-ups and 
other activities aimed at changing the lifestyle in question, thus increasing the benefit of treatment. Those who refuse to sign such a contract is given lower priority on the waiting list.[12] On this account, healthcare personnel should not indulge in whether "it would have been obtainable for one in the patient's circumstances to make a greater effort to get a healthy lifestyle in the past."[12] Thus, the notion of responsibility is forward-looking. The remainder of this article critically engages with Feiring's position. The first section elaborates the implications of Feiring's view through a closer look on the values underpinning it. It shows that her position should be applied to a broader range of cases than her discussion suggests. The second section criticizes her conceptual distinction between responsibility in past and future, while the third section argues that her suggested way of dealing with non-compliers is inconsistent.

\section{Elaborating on the implications of Feiring's position}

This section elaborates on the implications of Feiring's concept of forward-looking responsibility through an examination of the values underpinning it. On a fundamental level, her reasoning is contractual; searching for a principle people cannot reasonably reject. In the more specific arguments for her position, she presents two moral values in support of her concept of forward-looking responsibility. This section presents those values and labels them increasing benefits and reciprocity respectively. Increasing benefits stems from the plausible thought that we should be attentive to how much good the provided resources will do for the person they are allocated to. Feiring embraces this value, when she writes that "ill patients who are likely to respond well to treatment (within given resource constraints) should, under the specified understanding of medical need, be given priority over patients less likely to benefit."[12] According to Feiring, this value justifies giving priority to those who agree to change their lifestyle, because it increases the expected benefit of treatment.' Feiring's contractual idea is that people cannot reasonably reject this position.[12]. The value of reciprocity is expressed when Feiring claims as follows: "when resources are limited we owe each other to do what we can to make medical treatment efficacious".[12] It is even clearer when she writes the following: "when deciding on the terms on which we want to live with one another, it is reasonable to expect people to make

\footnotetext{
'This only holds if it is true that (1) people who change their lifestyle benefits more from the treatment; and (2) That those who enrol in such programs are more likely to succeed in such a change. I have no quarrel with such assumptions and will not discuss them further.
} 
do with their fair shares."[12] It seems plausible to suggest that reciprocity concerns what we owe to each other in a mutual relation. On that note, Feiring argues that we owe it to each other to change our lifestyle to increase benefits of treatment. Agreeing to such a change becomes a necessary precondition for receiving treatment on equal terms. Before presenting the critique of Feiring, her concept of forward-looking responsibility will be elaborated upon to show that it should be applied much broader than her discussion suggests. Feiring explicitly deals with persons who have a condition which may or may not be caused by the health risks associated with a specific lifestyle (a lifestyle which they may or may not have been able to change in the past), but where a continuance of this lifestyle decreases the expected benefits of treatment. But is the concept not applicable to a whole range of other diseases unrelated to lifestyle? Suppose a person broke his arm in a traffic accident or acquired a large wound on his leg while working. Since smoking slows down the process of healing, the benefits of treatment would be increased if the person undertook a change of lifestyle. Thus, the following seems to be in accordance with Feiring's position and the values she explicitly acknowledges: people should be asked to change their lifestyle when it will increase the benefit of treatment, regardless of whether the chosen lifestyle could have caused the medical need or not. Furthermore, people should be given lower priority in the healthcare system if they decline to do so. Such a broader application of the concept of forward-looking responsibility could and should be welcomed by Feiring, but will not be exploited in the critique that follows.

\section{CRITIQUE OF FEIRING}

Today was the future yesterday: Feiring's inconsistent cut between past and future" In this section it will be argued that Feiring's differentiation between the choices facing us before and after we become ill is arbitrary and ultimately saddles her with a strange view on responsibility. Do the values of increasing benefits and reciprocity commit us to increase the benefits of our share of resources and to minimize the amount of extra resources needed to treat us in the future? According to Feiring, this is the case at $t 2$, when a person is asked to commit to a lifestyle change as a precondition for receiving treatment, and at (an eventual) $\mathrm{t} 3$ when a new medical need arises related to the same lifestyle. But is it also the case at $\mathrm{t} 1$,

\footnotetext{
"The possibility that Feiring could accept this broadening was suggested by both reviewers.
} 
before the medical need arises? Feiring denies this. Drawing on an example from Scanlon, it will be argued that the distinction between past and future choices is less crucial than Feiring suggests.

The local town council is tasked with the removal of hazardous waste. The health risks of leaving it be would be huge, but removing it involves a much smaller although significant health risk (i.e. chemicals evaporating into the air during transport).[13] The town council does as much as could be expected of them in notifying the citizens prior to the event, and in shielding the relevant digging sites. Person $\mathrm{C}$ receives the information and chooses to travel to the site, climbs the fence and gets sick as a result. Adding to Scanlon's familiar story, suppose that in addition to making people sick the exposure also makes them extra vulnerable at a possible later exposure. On Feiring's account, person $\mathrm{C}$ must pledge to avoid such risks in the future, and compliance becomes a precondition for treatment on equal terms with others. Person C makes such a commitment. As it happens, another chemical deposit must be moved on a later occasion. Person $\mathrm{C}$ gets sick as a result of acting as before, with all else remaining equal.

This modified example raises serious doubts over Feiring's sharp distinction between the concepts of backward- and forward-looking responsibility. In her own reasoning, Feiring leans on a view on responsibility often associated with Scanlon. Here, responsibility has to do with whether something bad (or costly) was avoidable, and we might add that we also care about how difficult or costly it was to avoid.[13,14] Such a view on responsibility is neutral on the subject of time. Instead, it sets up a number of conditions that must be in place before a person can be said to be responsible for a state of affair. Whether such conditions are in place can change over time, but which factors that are relevant should not. The example with person C shows that Feiring's position is inconsistent. On Feiring's account, person $\mathrm{C}$ will only suffer the consequences for his imprudent behaviour the second time, even though other factors were equal. This is counter-intuitive and suggests a questionable view on responsibility. Consequently, when Feiring argues that people's posttreatment behaviour can be taken into account, we really should be wondering why this is not the case with pre-treatment behaviour. The right question to ask must be under which conditions people made their choices, which alternatives were available to them and how difficult or costly it was to pursue those alternatives.

It can be the case that such information is difficult to uncover or that trying to do so is 
demeaning or wrong towards people. But that applies equally at $\mathrm{t} 1, \mathrm{t} 2$, and $\mathrm{t} 3$, and it gives us no reason to talk of responsibility only at $\mathrm{t} 2$ and $\mathrm{t} 3$. Could it be that that the conditions are different at $t 3$. A last attempt to uphold such a view would be to submit that the people at $\mathrm{t} 1$ have failed to comply with a value but they have not failed to meet the specifications of a contract."I Such an objection cannot rescue Feiring's position. For suppose we gave every able-bodied and able-minded person a choice once they reached adulthood asking them to commit to a healthy lifestyle and to attend counselling regarding healthy living in general. $^{\text {IV }}$ The choice presented to these young people is parallel with what Feiring proposes we ask those that become sick and accordingly we can give priority to those who promised to change their lifestyle. The normative prominence Feiring gives the distinction between past and future choices thus seems implausible. It saddles her with a questionable view on responsibility, which passes vastly different judgment on identical situations.

\section{Consequences for non-compliers}

This section examines a critique of how Feiring's account treats those who agree to change their lifestyle but fail to do so. The strength of this critique is independent of the arguments presented so far, and thus proceeds as if the distinction between backward-looking and forward-looking responsibility can be upheld. Thus, the section proceeds as if we are justified in refusing to take people's past choices into account.

Consider person $D$ who has lifestyle disease $x$, lives a lifestyle with risk $r 1$ associated with disease $x$. At $t 2$, person $D$ agrees to change his lifestyle and is therefore given treatment i2 on equal terms with others. Person $D$ fails to change his lifestyle, and at $t 3$ he once again turns to the healthcare system for a medical need associated with $r 1$. How should we deal with person D? Feiring maintains that failure to live up to one's commitment should weaken one's claim for assistance: thus it would seem that person D is not allowed to sign yet another contract promising to eliminate $r 1$ from his lifestyle. It will be argued that the terms Feiring offers those who do not live up to the agreement they entered should a new medical need arise, are in conflict with her two critiques of backward-looking responsibility: that it is very difficult to assess what counts as choice and what counts as circumstance, and, furthermore, that a process of clarifying it could potentially be a demeaning and intrusive

\footnotetext{
III A point raised by an anonymous reviewer.

IV This point was suggested to me by (removed in order to keep review anonymous).
} 
process. Her views on responsibility at $\mathrm{t} 2$ and $\mathrm{t} 3$ are thus inconsistent.

Consider a given individual living a life with an unhealthy lifestyle. Such a lifestyle can be pictured as a long series of choices. The content of the choices has to do with avoiding something which is unhealthy, or conversely with doing something which is healthy. According to Feiring, we are unable to satisfactorily determine whether this lifestyle and the choices it consists of are most fittingly attributed to circumstances or can be considered genuinely related to choice. Considering this understanding as a plausible view on past events is admitted for the purpose of argument. At some point, $t 2$, this lifestyle leads to a medical need. On Feiring's account, , the person must choose to commit to a lifestyle change to receive treatment on an equal footing with others. Having received the treatment, the person will face a new series of choices, the content of which is much similar to those before the treatment. If the person does not live up to his commitment to lifestyle change and a new medical need arises, Feiring would allow it to affect future access to healthcare. Thus, Fering believes that we are unable to assess the degree to which the lifestyle choices leading to an illness are chosen, but if a person continues to make such choices after commitment to a lifestyle change, consequences are justified. If we cannot assert whether the choices leading to the first instance of medical need were actual choices, why should we fare any better with the choices that led up to the second? If we cannot justifiably let the first series of choices result in differentiation in treatment or waiting time, why then let the second series of choices do so? Presumably, the choices made after the commitment to a lifestyle change is undertaken are as much affected by circumstances as the previous ones. The concern here is thus, if Feiring is correct in her view that at $\mathrm{t} 2 \mathrm{we}$ cannot take past choices into account, why does this line of thinking not apply to the case at $\mathrm{t} 3$ ? Eventhough the choices regarding post-treatment lifestyle is indeed ahead of us when we promise to change our lifestyle to increase the benefits of treatment, this is not the case when we turn to the healthcare system on a later occasion with a similar medical condition, an unchanged lifestyle and thus in the light of non-compliance. At this point all this is very much in the past.

Feiring's positions of forward-looking responsibility furthermore seem to overlook how people's circumstances affect their abilities to fulfil their commitments to lifestyle change. This is quite remarkable since her critique of luck egalitarianism and backwardlooking responsibility was built around such a concern. Consider again person C, from the 
example of removal of hazardous material. For the purpose of the argument, it is admitted that Feiring is correct in giving him the option at $\mathrm{t} 2$ to avoid futureexposure. But suppose that the first exposure severely reduces his capacities and judgements. He agrees to avoid future exposure, but nevertheless fails to comply with the agreement. Intuitively, we would not count such a breach of agreement against him. But Feiring must submit that we should. The most obvious solution available to Feiring would be to suggest that how we treat people's second instance of medical need related to a specific lifestyle or choice of action should depend on an individual assessment of the effort made to follow through on the commitment to a lifestyle change. We could perhaps inquire into their own reasons for this failure, how often they attended the required meetings and how the medical staff judged their commitment to the required program. Presumably, people do differ in their efforts and in the extent that their failure can be explained by social circumstances. Some would have good reasons for non-compliance and others would have ignored instructions, failed to honour agreements and showed a lack of effort. If we tried to assess which is which, one could argue that the above concern over the influence of circumstances on people's ability to change their lifestyle could be mitigated. However, this most plausible solution cannot consistently be applied by Feiring, since she argues against backward-looking responsibility that any attempt at assessment may involve shameful revelations and be demeaning for the person whose choices and circumstances are under assessment. Those who would like to argue that this is too simplistic a view on our methods of retrieving information should acknowledge that this argument would be open to those favouring backward-looking responsibility as well. In conclusion, it would seem that any plausible version of Feiring's forward-looking responsibility, that is any position which involves actual consequences when people fail to live up to the agreements they have entered into, will seem vulnerable to at least one of the critiques she laboured against backward-looking responsibility. Even if Feiring is right (as doubted in the previous section) that we should treat pretreatment and post-treatment behaviour in radically different ways, her treatment of noncompliers is inconsistent with what she states elsewhere. Furthermore, her position is less attentive to social and natural circumstances than any luck egalitarian approach would ever be (since any breach seems to count against people). 


\section{CONCLUSION}

The above sections discussed three important elements in Feiring's concept of forwardlooking responsibility. First section elaborates on who the concept is applicable to by presenting arguments that it should be applicable in a broader way wider sense than her discussion suggests. Second, and more profoundly, the values she subscribes to suggest that people should act in ways to take care of their health and that failure to do so should result in lower priority in the health care system. Our past choices matter, and the strong normative emphasis she places on the distinction between past and future saddles her with an implausible view on responsibility. The third section considered how Feiring's account treat those who fail to live up to the agreements made prior to receiving treatment. It submits that the consequence she allows of such non-compliance is inconsistent with what she writes elsewhere, and it is surprisingly inattentive to people's circumstances.

\section{ACKNOWLEDGEMENTS}

(omitted for review)

\section{REFERENCES}

${ }^{1}$ Lippert-Rasmussen K. Arneson on Equality of Opportunity for Welfare. Journal of Political Philosophy 199;7:478-87.

${ }^{2}$ Buyx AM. Personal responsibility for health as a rationing criterion: why we don't like it and why maybe we should. Journal of Medical Ethics 2008;34:871-74.

${ }^{3}$ Cappelen AW, Norheim, OF. Responsibility in health care: a liberal egalitarian approach. Journal of Medical Ethics 2005;31:476-80.

${ }^{4}$ Cappelen AW, Norheim OF. Responsibility, fairness and rationing in health care. Health Policy 2006;76:312-19.

${ }^{5}$ Glannon W. Responsibility and priority in liver transplantation. Camb Q Helath Ethics 2009;18:23-35.

${ }^{6}$ Roemer J. A pragmatic theory of responsibility for the egalitarian planner. Philosophy and Public Affairs 1993;22:146-66.

${ }^{7}$ Segall S. Health, Luck and Justice. Princeton, NJ: Princeton, 2010. 
${ }^{8}$ Moss AH, Siegler M. Should Alcoholics Compete Equally for Liver Transplantation? The Journal of the American Medical Association 1991;265:1295.

${ }^{9}$ Sharkey K, Gillam L. Should patients with self-inflicted illness receive lower priority in access to healthcare resources? Mapping out the debate. J Med Ethics 2012;36:661-65.

${ }^{10}$ Veatch RM. Transplantation ethics. Washington, D.C.: Georgetown University Press, 2000.

${ }^{11}$ Veatch RM. Just Deserts? Hastings Center Report 2007;37:4-6.

${ }^{12}$ Feiring E. Lifestyle, responsibility and justice. Journal of Medical Ethics 2008;34:33-36.

${ }^{13}$ Scanon T. What we owe to each other. The Belknap Press of Harvard University Press.

${ }^{14}$ Cohen GA. On the currency of egalitarian justice. Ethics 1989;99:906-44. 